\title{
Malignant Pancreatic Somatostatinoma
}

National Cancer Institute

\section{Source}

National Cancer Institute. Malignant Pancreatic Somatostatinoma. NCI Thesaurus. Code C67369.

A malignant neuroendocrine tumor arising from the delta cells of the pancreas. It is characterized by inappropriate secretion of somatostatin and associated with diabetes mellitus, hypochlorhydria, gallbladder disease, diarrhea, steatorrhea, anemia, and weight loss. It displays vascular invasion and metastasizes to other anatomic sites. 